\title{
The Construction of Distance Education of Elite Athletes in the Education of Cultural Quality Guarantee System
}

\author{
Xueda Yang, Xiangdong Liu, Youzhi Zong \\ Yanan university sports institute yan 'an 716000
}

\begin{abstract}
The healthy and harmonious growth of excellent athletes relates to not only the development of the athletes themselves, but also the benign development of the country sports enterprise. Through the questionnaire, this study investigates Chinese athletes' cultural quality and proposes that it's very necessary to carry on the distance education system. in China. Besides, the construction of a remote cultural is also put forward when concerned with the athletes' professional knowledge and reference computers. The goal of this study is to improve the athletes' cultural quality in our country by the use of internet.
\end{abstract}

Keywords-building; Excellent athletes; Culture and education; Distance education

The continuous development of society and progress promotes the all-round development of people; the allround development of people also promotes social development and progress. They both have a stable internal relation and promote each other relations. The Eighteenth National Congress of the CPC requires full implementation of cultural construction and promotes the coordinated development of modernization construction at each aspect. Expectations of elite athletes' education with the development of society and progress are also rising, and different background of athletes receives different culture education form. The cultural quality education of excellent athletes to some great degree is the athlete culture education and facing the social adaptation and transformation of the crisis. The transformation from the planned economy system to market economy system requires us to change our traditional understanding of the athletes' cultural education concept. The understanding of the athlete culture education can not simply or simply stay in the single "cultural knowledge learning" at the low-level, but should be viewed broadly and comprehensive of the athlete culture quality education, to conform to the athlete the era of growth environment. Building the culture education of excellent athletes security system is a matter of elite athletes, career planning is related to the sustainable and healthy development of competitive sports. From the perspective of the Internet, this paper aims to improve the cultural quality of our athletes and athletes' culture quality by the distance education teaching so as to build continuous, open, and thus more comprehensive and convenient cultural security system.

\section{RESEARCH METHODS}

The research methods in this paper include literature material law, expert interview and questionnaire. The ques- tionnaire is about the culture quality education of excellent athletes' security system in Shaanxi province. There are 150 questionnaires, 125 recycled and the recovery rate is $83.3 \%$. But there are 105 effective questionnaires and the effective rate is $84.0 \%$ (coaches 30 questionnaires, and management of cadres 42, academic teachers 33).

\section{THE RESULTS OF STUDY}

\section{A. Understanding of cultural and current education situation of athletes}

It is pointed out that in "agenda 21" the history of education could promote sustainable development and it is the key to improve the ability of people to solve the problem. Results show that from an overall view, the attitude of subjects is obviously different. Engaged in competitive sports training of coaches and the performance appraisal of management cadres at various levels located in obtain explicit indexes such as performance, so that in their cultural education of excellent athletes was generally satisfied, you can tell the difference between a job responsibility, the pursuit of performance and indicators. Coaches pay attention to performance management cadres at various levels but ignore the cultivation of humanistic quality and overall career development and planning. On the contrary, it should be engaged in basic course teaching of teachers and coaches and management cadres at various levels. Besides, the education department and the sports department should pay more attention to how to acquire harmonic performance of excellent athletes in our province and realize the contradiction between culture and education.

\section{B. Investigation on the current cultural education system}

Scientific excellent athlete culture education system should be ecological, sustainable and harmonious. It should affect the person's ideas, improve people's quality and change people's behavior. But if the athletic level has been effectively promoted, it can provide dynamic support for the athlete individual career development. Results overall, the athlete culture education system should meet the needs of the athletes cultural learning. The adapt ability of evaluation should not be high. Athletes' current cultural education system reform has become inevitable.

Education is a social activity and people are the starting point and subjects of education. For a good natural ecology, cultural diversity is the necessary premise of good cultural ecology. Athletes in our country because of the specialization of early age, especially gymnastics, swimming, table tennis and so on, can't get the complete cultural education. 
They are intervened by some quick success at the same time, ignoring that the competitive sports team culture education is an indisputable fact. This requests us in the athlete culture education, to use dynamic and continuous point of view. We need to put the athlete culture education into the specific environment to study and pay attention to athletes' culture quality education and the related influencing factors of action and reaction. That is conducive to the flow of talents of competitive sports and harmonious development. We should adapt to today's social development and the objective requirement of the education reform.

\section{THE NECESSITY TO CONSTRUCT THE DISTANCE EDUCATION SYSTEM OF EDUCATION OF ELITE ATHLETES IN SHAANXI PROVINCE}

Education management of athletes in our country usually adopts the traditional way of management, especially the management of the athletes in our province. At different times, from the point of view of the development of people, the natural physiological and psychological state is different. Because of the different types, different populations society and the cultural quality, they belong to different social economic development level and thus leading to the thought idea, the behavior way and degree of difference. Material or spiritual relationship with human and social life is most closed. We can say without the need of human and social life, material or spiritual will lose its existence value. Athlete is a social person, his nature essence decides he cannot be live without material and cannot be influenced by social factors. But the athlete spirit is the core of the athlete culture. The symbol should be the power of social solidarity, forge ahead, and strive. Athletes' culture quality education problem reflects some characteristics of modern education but presents some new characteristics and properties. And remote education, as the perfect combination of modern Internet and education, makes the athletes can be anywhere at any time with the help of the Internet and they can also learn the related cultural knowledge.

\section{Build OUtSTANDing ATHLETE CULture EDUCATION SECURITY}

Culture is the basis of civilization, only the development of human culture reaches a considerable level, civilization will produce. Foreign athletics sports reserve talented person raise, which mainly depends on the education system and gradually forms a "university, middle school, elementary school". One-stop sports reserve personnel training system. Research shows that the athlete culture education guarantee strength is weak. There is a perfect running system but lack of educational funds. Many problems exist in teaching facilities and faculty structure. Our province real culture education of excellent athletes' security system directly relates to the important task of our province competitive sports so as to keep a sustained, healthy and rapid development.

\section{A. Outstanding athlete culture education system of new architecture}

Material or spiritual relationship with human and social life is most closed. We can say without the need of human and social life, material or spiritual will lose its existence value. Athlete is a social person, his nature essence decides he cannot be live without material and cannot be influenced by social factors. But the athlete spirit is the core of the athlete culture. The symbol should be the power of social solidarity, forge ahead, and strive. Athletes' culture quality education problem reflects some characteristics of modern education but presents some new characteristics and properties. In the current competitive sports culture education, the culture education of excellent athletes is not qualified with a rigorous structure. It is important to build a reasonable, scientific and cultural education system.

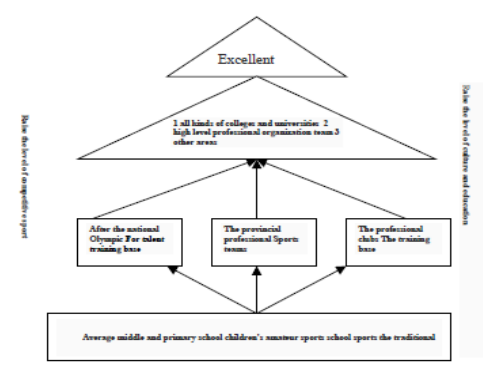

Figure 1 In shaanxi provice outstanding athlete culture education system in the architecture

\section{B. Guarantee excellent athletes culture quality education of the remote teaching system architecture design}

The construction of excellent athlete culture education system and integration is more and level is more, more functional departments. Because of the difference of sport itself, a larger gap between the age forms. That will ensure that athletes of different ages accept students section is education, promoting the culture education of excellent athletes of multilayered, to adapt to the demand of the social development and the current education reform in the future. Therefore, we will have different degree and hierarchical classification, and different teaching content presented to different teachers in order to guarantee the system of multilevel needs.

Secondly, with the design of the system, we adopt B/S mode. The way of the whole system can be divided into three layers architecture, through the web page to the customer's request directly to the user. The specific hierarchical architecture design is shown in figure 2. 


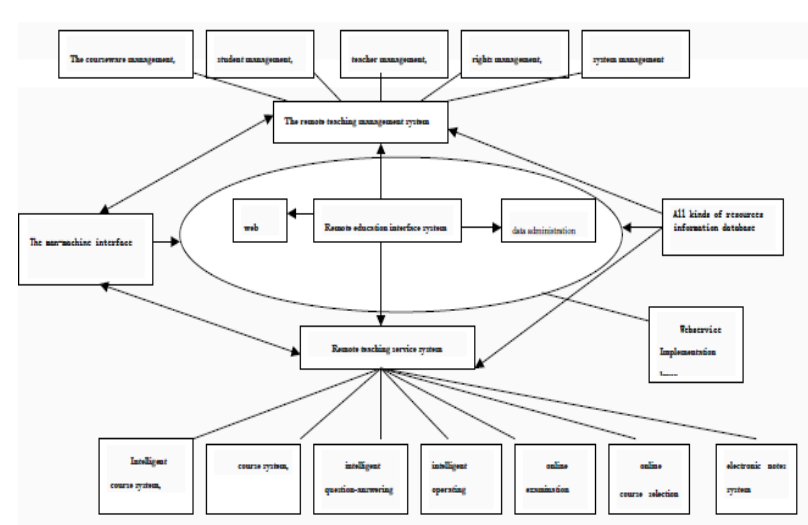

Figure 2 System level architecture diagram

\section{IMPLEMENTATION SUMMARY}

Everything follows the development of the inherent law of development, we can promote the benign development of things, and things can help to improve. Excellent athletes contributing to the development of competitive sports of the youth and strength, win the honor for our country. The development of the athletes should follow the historical, social, and cultural education security system stage characteristics. In addition, the distance education can offer the multichannel and multi-level of various forms of running a school and an effective operation mechanism. Through the construction of the distance education teaching system, the athlete's culture and quality can be improved. In this way, the development of competitive sports of our country will be guaranteed and it can be served as the powerful backup. At the same time, we need to accelerate the pace of reform of quality education, strengthen the compulsory education stage of the athlete culture education work, establish and build a suitable system to Chinese national conditions and the actual athlete culture education in our province, complete excellent athletes in sports training culture education teaching system so as to ensure the excellent athletes to have an overall comprehensive quality of ascension.

Fund project: 2013 in Shaanxi province department of education scientific research plan (special), humanities and social science project, project number: 2013 jk0514

\section{REFERENCES}

[1] Ye Muhua. athletes the cultural ecological construction [J], journal of hebei institute of sport: 2010 (5) : 30-33

[2] Li Jiang, Cai Mingming, Su Xinrong. Construct the culture education of excellent athletes security system research $[J]$, journal of nanjing institute of sport: social science edition, 2009 (3) : 11-14

[3] Yu Chonggan etc. After working culture education of excellent athletes in our country status report [J], sports science, 2008 (7) : 26-36

[4] Liu Yingmei. of professional athlete culture education [J], journal of institute for advanced study in military sports, 2012 (3) : 75-78

[5] Wang Kaizhen,Pan Zhichen etc. The analysis of the lack of culture education of excellent athletes in China and thinking [J], journal of capital institute of physical education, 2008 (1) : 1-4

[6] Tan wanning. Under the system of national professional athlete culture quality capital obtains and mess [J]. Journal of Chengdu sports college, 2001 (6) : 28 